\title{
The PPP and Equilibrium Exchange Rate of RMB
}

Gao Xiaolong* and Zhang Zhixin

Department of Economics, Shandong University of Technology, Shandong Province, China

*Corresponding author: Gao Xiaolong, Department of Economics, Shandong University of Technology, Shandong Province, China, Tel: +15269394597; E-mail: 15269394597@163.com

Received date: July 26, 2016, Accepted date: August 26, 2016, Published date: August 30, 2016

Copyright: $\odot 2016$ Xiaolong G, et al. This is an open-access article distributed under the terms of the Creative Commons Attribution License, which permits unrestricted use, distribution, and reproduction in any medium, provided the original author and source are credited.

\begin{abstract}
This paper compares various methods of measuring the equilibrium exchange rate. We believe that it should be considered the three aspects of essential attribute of the exchange rate, the economic situation and regulating needs of policies when it comes to the measure of RMB equilibrium exchange rate. The paper points out that the extended PPP method is more appropriate than the FEER approach and it is a "second-best" choice. Then we make a systematic review of the literatures and commentary on how to measure equilibrium exchange rate properly with the application of PPP. We believe that the extended PPP approach would be better suited to measure RMB equilibrium exchange rate than the other relative PPP methods. According to the PPP data published in 2005 by the World Bank, we have successfully countered and interpret a series of statement which were suspected overvaluation of Chinese PPP, accordingly it is very difficult to reach the conclusion that RMB exchange rate has been seriously underestimated, which mean that the current price level in China is compatible with the economic level and the ratio of prices with other countries is basically normal.
\end{abstract}

Keywords Equilibrium exchange rate; PPP; RMB; FEER

\section{Introduction}

For some time, almost all the researches about equilibrium exchange rate of RMB, though in different method and index, got the same conclusion that RMB has been undervalued, the only difference is the levels of underestimation. Moreover, as the issue of RMB undervaluation becomes political topic and bargaining chip, the version of RMB underestimation, to some extent, seems to have no two ways about it. When all think that it has no need to argue about, the turning point appears. In February 2008, ICP announced a new data of PPP which showed that: the rate of purchasing a standard goods and services in U.S. dollar and RMB is 1: 3.45 [1].

This means that China's PPP has been increased by $40 \%$ with new data comparing with the World Bank's data used before. That is to say, the equilibrium exchange rate of RMB calculated with extended PPP method based on "PENN effect" and the new data has no undervaluation, or even overvalued seriously if counting according to the modified extended PPP method. Cline and Williamson pointed out that the 18 studies summarized reveal that the literature offers widely differing answers, even sticking to post-2000 estimates and even when one recognizes, as not everyone has done, that an effective exchange rate is a totally different creature from a bilateral dollar exchange rate and that one should expect estimates of undervaluation on each concept to be quite different. The key conclusion is as following: However, of all 18 studies, only one tries to argue that the RMB might be overvalued. Moreover, the average estimates indicate substantial undervaluation. The simple average of the 14 estimates of the correction needed in the real effective exchange rate is a 19 percent appreciation; the corresponding simple average of the 16 estimates for the bilateral rate against the dollar is an appreciation of 40 percent. The undervaluation shows signs of growing worse over time, as the average real effective appreciation needed rises from 17 percent in studies using data from the period 2000-2004 to percent in those using data from 2005-2007.

Before 2008, we can see the conclusion that the level of RMB underestimation with the method of PPP directly is more than $50 \%$. There are even more excessive studies. Subramanian [2] said that: New estimates for the undervaluation of the Chinese currency based on the purchasing-power-parity approach yield a figure that is closer to $30 \%$ rather than the $12 \%$ reported recently. These estimates, all of which come with qualifications and caveats, are based on applying new insights about the way in which the PPP data are compiled, using new data that have become recently available, and correcting existing estimates for the biases in the data used for China in particular. The best PPP-based estimate for RMB undervaluation is one that can combine the methodology suggested by Johnson with data that corrects for the biases in the 2005 ICP project. It will be possible to undertake such an estimate when version 7 of the Penn World Tables, which will correct for some of the biases in the 2005 ICP data and hence in the World Bank's WDI PPP estimates, is released later this year. But for now, the best (or at least the least problematic) PPP-based estimate for RMB undervaluation remains about $30 \%$.

Combining with the unmatched special status of PPP to traditional exchange rate theory, researchers are convinced of the argument of $\mathrm{RMB}$ underestimation. But the new conclusion with the new data triggered the most intensive debate equally because of the special important status of PPP.

As the emergence of this contradiction, it goes the following questions naturally: which is the most appropriate method measuring equilibrium exchange rate of RMB among varied methods? Is the equilibrium exchange rate of RMB undervalued, overvalued or normal? Combining with these questions, we discuss the various measurement methods of equilibrium exchange rate and point out that the PPP measuring method of equilibrium exchange rate of RMB is more proper in Sec.4. In Sec.5, we analyze several different forms of PPP and think that the extended PPP which is based on PENN effect 
Page 2 of 5

and can be better able to apply to China's economic situation is appropriate to measure equilibrium exchange rate of RMB. In Sec.6, we choose the World Bank's new data to argue about the equilibrium exchange rate of RMB with the extended PPP method and other controversies. We get that the current equilibrium exchange rate of RMB do not exist underestimation.

\section{How to Measure the Equilibrium Exchange Rate?}

Generally, the equilibrium exchange rate is an exchange rate level which is adapted to the internal and external economic balance. It is a long term concept and raises many academic controversies. The debate could be divided to two key points. First, the equilibrium exchange rate is existed and can be identified or not? Second, if existed, how to measure? From the perspective of economic theory, it is neither necessary identifying the equilibrium exchange rate, even less likely. From the consideration of actual facts, the exchange rate formed by market force is always equilibrium level. Meese et al. [3] compare the out-of-sample forecasting accuracy of various structural and time series exchange rate models. They find that a random walk model performs as well as any estimated model at one to twelve month horizons for the dollar/pound, dollar/mark, dollar/yen and tradeweighted dollar exchange rates. The structural models perform poorly despite the fact that the authors base their forecasts on actual realized values of future explanatory variables. And the later numerous studies also illustrate the correctness of this conclusion [4]. Although it is theoretically difficult and even uncompleted to measure the equilibrium exchange rate, it has to be estimated in reality for a variety of needs.

Assessing the equilibrium levels of exchange rate is an important responsibility of macroeconomic policymakers. Exchange rates have a major influence on the prices faced by consumers and producers throughout the world, and the consequences of substantial misalignments can be extremely costly. The currency crises experienced by a number of emerging-market economies over the past decade testify to the large output contractions and extensive economic hardship that can be suffered when exchange rates become badly misaligned and subsequently change abruptly. Moreover, there is reasonably strong evidence that the alignment of exchange rates has a critical influence on the rate of growth of per capita output in low income countries [5]. Economists have developed a number of methodologies for assessing equilibrium exchange rates. Each methodology involves conceptual simplifications and imprecise estimates of key parameters; and different methodologies sometimes generate markedly different quantitative estimates of equilibrium exchange rates.

Isard [5] described six different methodologies that have been used to assess the equilibrium values of exchange rates and discussed their limitations. And grouped into two categories, namely price-based PPP method and macroeconomic approaches from the perspective of balance, in which the latter takes fundamental equilibrium exchange rate (FEER) approach discussed by Williamson [6] as represented, including behavioral equilibrium exchange rate (BEER), desired equilibrium exchange rate (DEER), natural real equilibrium exchange rate (NATREX) and so many other methods.

$\mathrm{He}$ pointed that different approaches sometimes provide substantially different assessments, and which methodologies deserve the most weight in such situation. While it is generally desirable to consider the implications of several different approaches, since different approaches provide different types of perspectives, two of the methodologies seem particularly relevant for identifying threats to macroeconomic stability and growth. These methods are complementary, especially if the PPP method and FEER method get more consistent conclusion, it shows that the conclusions are appropriate [2]. But how should national policymakers choose among approaches if they are primarily interested in assessing their own exchange rates and have limited resources to devote to assessment exercises? It should be noted-as many policymakers have emphasized-that there is no general answer to the question of what to do when an exchange rate is judged to differ substantially from its equilibrium level. Exchange rate adjustment is not always the best answer or the only part of the answer. Policy advice on the best course of actionwhether viewed from a global perspective or the perspective of an individual country's ultimate targets-needs to be framed in the context of an overall assessment of the prevailing macroeconomic situation and the risks to the macroeconomic outlook. When it comes to estimate the equilibrium exchange rate of RMB, we should take the following three into consideration: Essential attribute of the exchange rate, the economic situation and regulating needs of policies.

\section{Essential attribute of the exchange rate}

The methodologies which used to assess the equilibrium values of exchange rates should be consistent with exchange rates' essential attribute. The exchange rate is a piece of relative price which reflects the ratio of goods and services between countries. It would help to achieve internal and external balance when the relative price is at a reasonable level. The exchange rate distortion is bound to lead to resource misallocation and thus brings the various economic imbalances, but conversely may not hold. Macroeconomic imbalances could not infer the conclusion of exchange rate disorder for granted. Even if the relative price level is in a reasonable state, institutional deficiencies, policy interference, sudden shocks and other factors will make the economy fall into the short-term or long-term internal and external imbalances which should not be solved by exchange rate adjustment.

The core of PEER methodologies is to achieve a certain target of current account through exchange rate adjustments, basing on the precondition that the exchange rate can adjust current account effectively. However, a modest adjustment effects which produced by the exchange rate for current account even in the short term have not been confirmed by rigorous empirical research up to now. Currency depreciations or appreciations that change the relative competitiveness of producers in different countries are undesirable from a global perspective if they lead to relative prices that do not reflect the true relative costs of production. From this standpoint, "external balance" does not mean that trade balances should be zero, but rather that global resources are allocated efficiently. The implications of this insight for the role of the exchange rate in monetary policy are explored here [7]. It is highly controversial whether the exchange rate of RMB has an effect for current account adjustment. Since FEER approach has theoretical significant deficiencies, it is very dangerous to make use of this method to guide policy practice.

\section{The economic situation}

The methodologies which used to assess the equilibrium values of exchange rates should be consistent with the economic situation. As an economy of rapid growth and urgent transformation, China has its special characteristics. To assess the internal equilibrium, the output 
gap in developing countries cannot adopt standards of developed countries, while the measure of external balance are facing more difficulties. From the point of stock, the rapid development of countries' overseas assets and debts is a continuous changing situation. Taking overseas assets and debts at steady state as equilibrium condition is clearly inappropriate. From the point of traffic, FEER approach facing a problem is how to solve contradiction between China's "double surplus" pattern and developing countries' theoretical "two-gap" model. For a long time, the most critical problem for fundamental equilibrium exchange is the determining criteria of external balance. Because the rational current account balance has no unified standards, researchers can only rely on subjective judgments, which would make this approach sink into so many value judgments colors. At least for China, small changes in model specifications, explanatory variable definitions, and time periods used in estimation can lead to very substantial differences in equilibrium real exchange rate estimates. Therefore, such estimates should be treated with great caution [8]. Considering of this, PPP method applied in use needs some corrects While FEER approach is difficult to utilize.

\section{Regulating needs of policies}

The methodologies which used to assess the equilibrium values of exchange rates should be consistent with regulating needs of policies. Economic development is the main task for China in quite a long time. So how to promote a sustainable and balanced growth may be the significant direction of policies, and these would be mainly reflected in the maintenance of reasonable and internationally competitive price level. The extended PPP approach elaborated the basic economic law that price level should be compatible with economic development situation which is confirmed by realistic data repeatedly. This provides a more objective and credible basis for seeking a reasonable exchange rate in different stages of economic growth. For FEER approach, on the one hand, it is so vulnerable to be affected by actual political factors that may lose its credibility. On the other hand, it is difficult to provide a longer period systematic development path which based on different stages due to its analysis interval within 3-5 years. Therefore, the FEER approach is difficult to meet China's control needs of policies.

Equilibrium exchange rate is quite hard to measure with uncertainty of various aspects like theoretical and empirical data. If we want to choose one to measure the equilibrium exchange rate of RMB between the PPP method and FEER method, considering essential attribute of the exchange rate, the economic situation and regulating needs of policies, we can know that the extended PPP method is more appropriate than the FEER approach and it is a "second-best" choice.

\section{PPP and Equilibrium Exchange Rate of RMB}

Over the last decade or so, the theoretical and empirical literature on equilibrium real exchange rates split into two parts. The first one relies on the traditional PPP theory. Whatever its validity as a very long run theory of equilibrium real exchange rates, PPP is not an operational concept in the medium to long run. This has led researchers to try to develop alternative theories of the equilibrium real exchange rate at such horizons, the so-called 'macroeconomic approaches', based upon departure from all versions of PPP. Just as discussed before, if we want to choose one to measure the equilibrium exchange rate of RMB between the PPP method and macroeconomic approaches which is represented of FEER method, considering essential attribute of the exchange rate, the economic situation and regulating needs of policies, we think PPP method is more appropriate for measuring equilibrium exchange rate of RMB.

PPP method could be divided into original PPP and extended PPP. The latter, based on "PENN effect" or "Balassa and Samuelson effect", points out that the price level of a country and its level of economic development are closely linked. Countries with backward economy will have lower price levels. Each method could be divided into relative PPP and absolute PPP. The former is designed to measure the dynamic direction and magnitude of exchange rate adjustment, while the latter is designed to measure the absolute level of the exchange rate. Taking use of extended PPP method is so international and popular that the original PPP is rarely used or not taken seriously since 2000 .

\section{Relative PPP method without extended}

Relative PPP points out that the change of exchange rate is determined by the relative inflation between two countries. Thus, the related discussions would fixed the exchange rate which is at some point as benchmark and after the period investigate whether changes in the exchange rate between the two countries reflect the related changes in the price level. The use of relative PPP is involved in two issues: Firstly, how to choose price index? Secondly, how to choose the benchmark? Different standards would bring different conclusions.

Strictly speaking, the relative PPP approach is not the good way to determine equilibrium exchange rate, while its main value lies in the analysis of the real exchange rate laws and other theoretical studies. For a long time, tests of PPP theory are mainly set up around the relative PPP theory within more lenient conditions. The focus is that whether the real exchange rate can reject the assumption of unit root process and reflect its stability. This leads to the "PPP puzzle": How can one reconcile the enormous short-term volatility of real exchange rates with the extremely slow rate at which shocks appear to damp out? Most explanations of short-term exchange rate volatility point to financial factors such as changes in portfolio preferences, short-term asset price bubbles, and monetary shocks. Such shocks can have substantial effects on the real economy in the presence of sticky nominal wages and prices. Consensus estimates for the rate at which PPP deviations damp, however, suggest a half-life of three to five years, seemingly far too long to be explained by nominal rigidities. It is not difficult to rationalize slow adjustment if real shocks-shocks to tastes and technology are predominant. But existing models based on real shocks cannot account for short-term exchange rate volatility.

There will be two problems to estimate equilibrium exchange rate with relative PPP method directly. First, it is related to how to choose the benchmark. The judgment of current equilibrium level is determined by that whether the exchange rate is in the balanced condition at the beginning point. Second, it has a serious shortcoming to assess equilibrium exchange rate theoretically, which is based on the real exchange rate stability as the theoretical premise. When it comes to China, an economy with rapid economic growth and enormous institutional changes which may make the real exchange rate tend to exhibit structural changes, this means that relative PPP is difficult to be used. Relative PPP generally can only apply to countries of the same level of economic development [9].

\section{Absolute PPP method without extended}

Absolute PPP without expending means that it determines equilibrium according to "law of one price" directly. This needs the raw data of different countries and many other requirements as 
Page 4 of 5

comparable. Therefore, an important issue of using this method is to judge the data's reliability. In the study, one method is to measure with a single commodity price data considering that it is easy to get the data. But this just reflects the prices in different countries of one good and could not substitute PPP. The relative price among countries is complex that not all prices in one county are lower than in another. Another is to measure with the data of a variety of goods and services as accurately as possible.

Reasonable data of PPP requires the coverage of all kinds of goods and services as broad as possible. This comprehensive cross-country price comparison is a very difficult and complex work. So World Bank International Comparison Program (ICP) has to undertake this task. The collected data are distributed in World Development Indicators (WDI) database and Penn World Tables database (PWT) provided by the University of Pennsylvania based on different principles. Before 2008, these data are based on statistics of ICP in 1993. Chinese PPP data is given by the prices comparison of GuangDong and HongKong, and then adjusted with the price index changing. For a long time, the data of China released by ICP in 1993 is not very precise that the purchasing power of U.S. dollar and RMB is 1: 2 . In another words, the prices of Chinese goods and services are equivalent to $25 \%$ in U.S. according to the market exchange rate. And in turn the underestimation of RMB is quite amazing.

It is rare to assess the exchange rate with the PPP data directly, because "law of one price" is applicable hardly even for tradable goods in reality [10]. In addition, the researchers also found that the price level of each country and its level of economic development have a very close relationship. It becomes the main method measuring the equilibrium exchange rate to extend from the perspective of closely relationship between price level and development.

\section{The extended PPP method based on "PENN effect"}

Gibert et al. [11] pointed the phenomenon in their article "An International Comparison of National Products and the Purchasing Power of Currencies". The major contribution of their study is certain to lie in the wealth of detail on GNP components and purchasing power equivalents. That's "PENN effect": There is a stable positive relationship between a country's relative price level converted by market exchange rate and the per capita GDP. If a country is more developed, the higher price it has.

According to "PENN effect", PPP is expended into the variables' regression analysis between national income and the real exchange rate. This analysis is carried out basing on the data of countries' general price and income level released by ICP. Statistical data of ICP is generally based on U.S. data as a basis of comparison ignoring that the dollar has not been overvalued or undervalued.

"PENN effect" is an ideal fit for the determination of RMB equilibrium exchange rate. First, the Balassa-Samuelson model offers a theoretical explanation for the "PENN effect". Since then most empirical tests of "PENN effect" have used cross-sectional data from the ICP. Every round of the ICP appears to have confirmed "PENN effect". Based on such evidence, the Wikipediaentry on the "PENN effect" describes it as "a consistent econometric result for at least fifty years" [12]. It is of the few economic laws that can be tested and verified repeatedly among the economics, which fully reflects its objectivity.

Second, "PENN effect" is consistent with exchange rates' essential attribute. As the real exchange rate which reflects relative prices relationships, it would shows systematic evolution characteristics at different stages of economic development. Since China is developed from low-income countries to the high-income countries gradually, it is obviously the most reasonable choice to follow this rule to determine the equilibrium exchange rate.

In addition, as the statistical data of transnational commodity prices may have a variety of deviation, therefore, this relationship can only assess a roughly reasonable range of the equilibrium exchange rate rather than specific measurement. However, considering the special situation of developing countries like China, the extended PPP approach can better fit the RMB exchange rate analysis if it takes various modifications in the use of the different actual situations.

\section{The new ICP data and estimation of RMB exchange rate}

In February 2008, the World Bank International Comparison Program (ICP) released new data which were estimates of Purchasing Power Parities (PPPs) in the year of 2005. PPPs are based on intercountry comparisons of the national annual average prices for a representative selection of goods and services. They convert nominal values in terms of the local currency to real values in terms of a common currency. More specifically, a PPP is defined as the number of currency units required to purchase the amount of goods and services equivalent to what can be bought with one unit of the currency of the base country. Notice that ICP 2005 is the first time China participated in the International Comparison Program. The previous PPPs for China were based on a bilateral comparison of the US and China in 1986, which was based on very limited data. In comparison, China's PPPs by ICP 2005 are based on comprehensive surveys in 11 cities, using more than 1,000 closely specified goods.

ICP 2005 is a huge undertaking involving 146 countries. As a result of the sheer scale and complexity of the project, ICP 2005 has been broken up into two stages. In stage 1, the countries are divided into six regional blocks. The regions are Africa, Asia-Pacic, South America, Western Asia, CIS and Eurostat/OECD. Separate comparisons are then made for each block. In stage 2, these regional results are linked together to generate the overall global results. This is achieved by means of a comparison between 18 so-called ring countries drawn from five of the regions, with at least two ring countries in each region [13]. The CIS is linked to Eurostat/OECD through Russia which participated in both the Eurostat/OECD and CIS comparisons.

ICP new data raised PPP level of RMB for $40 \%$. While the degree of RMB undervaluation estimated with the old PPP data is also about $40 \%$, there is no longer undervaluation directly on the data. Some researchers assessed the RMB exchange rate with the same method as before, but the new data shows that RMB is overvalued for $5 \%$, and even overvalued seriously if counting according to the modified extended PPP method. Because of the fundamentally opposite recognition, some scholars point out their doubts about the credibility of the new data. But more researchers would like to explore the possible elements which lead to deviations of RMB data on the basis of accepting the ICP data. They attribute the reasons into two points.

The first one, during cross-national statistics, the basket of goods selected products with different quality, price, and usability between the developed and developing countries. The more common in developed countries, the easier could be selected to basket of goods. These goods are rare but higher prices in developing countries. The corresponding similar products with low price in developing countries may not provide the same quality. So it could lead to the PPP 
Page 5 of 5

overvalued in developing countries. We think that the statement is lack of macro-comparative perspective. They say some goods in the basket may bring about PPP overvalued in developing countries, likewise another goods can result PPP undervalued as well. Additionally, the statistics has its universality so that all the developing countries would be overestimated or underestimated and it has little persuasive for real comparison.

The second one, ICP during the census, selected the data of 11 cities and their suburbs in Chinese mainland, but which did not include rural areas and the income of 11 cities are higher than the national average. So, they thought this would lead to overvalued of Chinese PPP. In this regard, we find that there are four regions which have similar problems in rural price data in the six regions of ICP statistics in 2005, except for the more developed OECD and CIS countries. Lack of rural data is a common problem in this statistics. If they think RMB undervalued basing on this, they should firstly guarantee this problem is not a common one.

In addition, though the rural price data is missing, the price level in rural and urban area is inconclusive to judge. Generally speaking, it is believed that the price level in rural areas is lower than that in cities due to its low rural labor costs, low rents and other factors. But there are many studies supporting the opposite view that it would have higher prices in rural areas which attributed mainly to the backward logistics and business form, the high price of electricity and communications. Therefore, this could not be the evidences of RMB undervaluation.

In summary, we can see that ironclad facts of RMB exchange rate undervaluation has already gone basing on the new data. According to economic theory and the corresponding exchange rate analysis method, it is difficult to judge whether the RMB exchange rate is overvalued or not, but it is certain that it has not been underestimated.

\section{Conclusion}

This article makes a systematic review of the literatures and commentary on how to measure equilibrium exchange rate properly with the application of PPP. We believe that the extended PPP approach would be better suited to measure RMB equilibrium exchange rate than the fundamental equilibrium exchange rate method. According to the PPP data published in 2005 by the World Bank, it is very difficult to reach the conclusion that RMB exchange rate has been seriously underestimated, which means that the current price level in China is in general terms compatible with the economic level and the ratio of prices with other countries is basically normal.

In addition, with the gradual disappearance of the demographic bonus and changes of factor income shares, China will face further wage increasing trend which would enhance our country's relative price level. At the same time, RMB normal exchange rate is going through the sharp appreciation constantly. Against this background, there may be significant overvaluation problem in China, which causes the currency value divergence between internal and external and a series of national economic regulation failures.

\section{References}

1. World Bank (2008) Global Purchasing Power Parities and Real Expenditure: 2005 International Comparison Program.

2. Subramanian A (2010) New PPP-based estimates of Renminbi undervaluation and policy implications. Peterson Institute for International Economics.

3. Meese RA, Rogoff K (1983) Empirical exchange rate models of the seventies: do they fit out of sample? J Int Econ 14: 3-24.

4. Rogoff K (2009) Exchange rates in the modern floating era: what do we really know? Review of World Economics 145: 1-12.

5. Isard P (2007) Equilibrium exchange rates: assessment methodologies. International Monetary Fund 4: 89-92.

6. Williamson J (1991) FEERs and the ERM. National Institute Economic Review 137: 45-50.

7. Engel C (2009) Exchange rate policies. Economics online.

8. Dunaway S, Leigh LA, Li X (2009) How robust are estimates of equilibrium real exchange rates: the case of China. Pacific Economic Review 14: 361-375.

9. Rogoff K (1996) The purchasing power parity puzzle. Journal of Economic literature 34: 647-668.

10. Gilbert M, Kravis IB (1954) An international comparison of national products and the purchasing power of currencies: a study of the united states, the united kingdom, France, Germany, and Italy. organization for European economic cooperation, Paris.

11. Ravallion M (2010) Price levels and economic growth: making sense of the PPP changes between ICP rounds. World Bank Policy Research Working Paper.

12. Hill P (2007) Ring comparison-linking within-region PPPs using between region PPPs. In: World Bank. Measuring the Real Size of the World Economy. pp: 225-243.

13. Crucini MJ, Shintani M (2008) Persistence in law of one price deviations: Evidence from micro-data. J Monetary Econ 55: 629-644. 